\title{
OOJED
}

Volume 5, Issue S1 (2020), pp. 55-60

Journal of School Administration Research and Development

ISSN: 2470-8496 Print/ ISSN: 2470-850X Online

ojed.org/index.php/JSARD

\section{Going the Distance: What School Administrators Can Learn from One-to-One Laptop Schools}

\author{
Miguel M. Gonzales \\ Iesha Jackson \\ University of Nevada Las Vegas, USA
}

\begin{abstract}
As a response to the COVID-19 pandemic, many school administrators are forced to transform traditional schooling into an online distance learning environment. This commentary addresses how some of the challenges and implications of our research in leadership and instruction of one-to-one laptop schools are applicable to establishing a distance learning environment alongside current standards for instruction. School administrators are strongly encouraged to collaborate with teachers as soon as teachers report for the school year to help create a shared vision of effective online instruction and implement supplemental frameworks that will guide evaluation of teaching and learning online.
\end{abstract}

Keywords: Collaboration, Instruction, Leadership, Standards, Technology

Education systems across the world have been deeply impacted by COVID-19. In an attempt to protect children and educators, more than 130 countries implemented nationwide school closures, affecting approximately $80 \%$ of the world's student population (UNESCO, 2020). As this school year begins, many schools in the United States have opted for distance learning. This disruption of traditional schooling has caused many educators to scramble to organize learning 
opportunities through online platforms. Teachers are now looking at school leadership all the more to help them navigate through this unprecedented time.

To help prepare schools for distance learning, some school districts are now purchasing laptops for distribution to students, transforming schools into what are known as one-to-one laptop schools. By definition, these are schools in which every student uses a laptop for curriculum and teachers provide technology-enhanced instruction. We see this current moment as an opportunity to convey pressing challenges and opportunities for providing one-to-one laptop instruction both in schools and through distance learning. This commentary is the result of our work with several one-to-one laptop schools in the state of Nevada. As authors, we gleaned insights regarding leadership and instruction in one-toone laptop schools to posit how administrators might more effectively support teachers in distance teaching and learning. We situate this work within school technology leadership research (McLeod \& Richardson, 2013) in order to highlight the potential of applying the International Society for Technology in Education (ISTE) standards through collaborative professionalism.

\section{MAIN ARGUMENT}

Although one-to-one laptop initiatives show great promise, research has indicated conflicting results regarding the impact of teacher pedagogy on student learning outcomes (Weston \& Bain, 2010; Zheng et al., 2016). This suggests it is a complicated task to transform into a one-to-one school, but even more complex is leading the transformation. For example, administrators sometimes implement one-to-one initiatives in a manner that is no different than traditional schools in terms of pedagogical innovation in part because they struggle to define and consistently promote best practices for online teaching. This unique issue of establishing an effective one-to-one learning environment has now become a major concern for all schools forced to implement distance learning. In response to changes brought about by COVID-19, school administrators must create an environment that is conducive to learning, risk taking, and growth with technology. Having a shared vision of school technology instruction is key to instructional improvement, especially now in a distance learning environment. While it is the responsibility of the school principal to help align a shared vision of one-to-one laptop instruction, our research suggests one of the main challenges to having an aligned vision of technology-rich instruction is using the teaching standards and teacher evaluation rubric to identify effective instruction with technology. We found (Gonzales \& Jackson, 2020) that misunderstandings between teachers and school administrators regarding instructional expectations 
for one-to-one laptop use can lead to a lack of a shared vision to improve collectively as a school. This issue is likely to be exacerbated in distance learning environments.

Instructional expectations are often determined by evaluation systems. By design, evaluation systems take a one-size-fits-all approach to teaching and learning in a given state or district. Very few, if any, are intended to establish effective pedagogical practices with technology. This has become even more urgent as teachers suddenly find themselves having to provide high quality instruction via distance learning with little-to-no guidance for what that means or how it should be evaluated.

In Nevada, the evaluation system is guided by the Nevada Educator Performance Framework (NEPF), which is intended to improve instructional effectiveness by evaluating student learning as well as educators' professional growth and development. The evaluation cycle has five distinct steps: (1) educator self-assessment, (2) pre-evaluation conference analysis with goal setting and plan development, (3) observations and conferences including plan implementation and evidence review, (4) mid-cycle goals review, and (5) postevaluation conference and end-of-cycle summative evaluation. The current teacher framework has two weighted categories: educational practice $(85 \%)$ and student performance (15\%). While the standards are arguably applicable in any teaching context, the increase of distance learning creates a need for administrators and teachers to better understand how to explicitly connect the NEPF to their expectations for teaching and learning online. Several teachers we interviewed indicated they were unclear about the expectations their administrators had for technology use during their formal observations. One teacher explicitly stated, "If you weren't going to evaluate a teacher's use of technology and you're going to try to evaluate that specific thing on the NEPF, you are doing it wrong." In the absence of clear guidelines to specify effective practice for one-to-one instruction, teachers also struggled to articulate how the initiative changed their approach to teaching. This highlights a need for administrators to better define high quality instruction for in-school and out-ofschool technology-based instruction

Since most, if not all, teacher evaluation rubrics do not address or translate what effective technology-based instruction looks like, teachers and school administrators have an opportunity to co-develop supplemental frameworks. One approach to this work is through collaborative professionalism (Hargreaves \& O'Connor, 2018), which relies on a supportive climate of trust, clear structures, feedback and expertise for joint work. The benefit of this approach is that the focus is on purposeful and directed improvement efforts. 
When principals work alongside teachers to co-construct an evaluation tool to supplement state frameworks lacking clear guidance, a collaborative professionalism approach would require principals to see themselves less as the instructional leaders of their schools and more as the facilitators of teacher learning and leadership. By doing so, principals will be able to establish with teachers a consistency of instructional expectations that will help guide not only their pedagogy with laptops but also inform more in-depth and personalized professional learning experiences. Such learning experiences and supplements to an evaluation framework should consider the ISTE (2020) standards for educators. The aim of these standards is to enhance student learning through the effective use of technology. Guiding principles include educators working to "set professional learning goals to explore and apply pedagogical approaches made possible by technology and reflect on their effectiveness," "model for colleagues the identification, exploration, evaluation, curation and adoption of new digital resources and tools for learning," and "design authentic learning activities that align with content area standards and use digital tools and resources to maximize active, deep learning"(ISTE, 2020, paras. 2 \& 5). A goal of collaborative professionalism in the context of improving teaching with technology might be to create a rubric for applying ISTE standards in conjunction with existing teacher evaluation systems.

School principals must establish a school vision that articulates not just what they do with laptops and why they do it but also an understanding of how they teach students with them. The craft of how to develop and model effective one-to-one laptop instruction needs to begin with the principal creating a culture of risk-taking with technology and allowing teacher collaboration to go beyond professional learning communities. Without taking these initial steps, providing teachers with professional development in technology instruction will always be incomplete and will atomize their successes rather than have them grow collectively.

\section{CONCLUSION AND IMPLICATIONS}

The roles and responsibilities of today's school principal are complex and constantly evolving. If principals are going to maximize student learning, they will need to reconceptualize their role as an instructional leader. To more effectively implement distance learning, school administrators should establish a shared vision for instruction with technology. The ISTE (2020) standards for school administrators provide a strong framework to accomplish this goal. These standards include empplying a(n) (1) Equity and citizenship advocate; (2) 
Visionary planner; (3) Empowering leader; (4) System designer; and (5) Connected learner. As school administrators begin to establish a one-to-one laptop school vision, ISTE standard Visionary Planner requires they engage all stakeholders "in developing and adopting a shared vision...[and] build on the shared vision by collaboratively creating a strategic plan that articulates how technology will be used to enhance learning" (para. 2). While the COVID-19 pandemic has compelled schools to implement distance learning opportunities, school administrators should take advantage to collect feedback from teachers on how technology has shaped their instruction and what effective instruction with technology should look like. Using teacher feedback will help prepare school administrators to establish a shared vision and place them in a calculated position to create a "strategic plan that articulates how technology will be used to enhance learning" (ISTE, 2020, para. 4).

Now that most schools have jumped off the boat of traditional schooling without a lifejacket and into the uncharted waters of online instruction, there is an increased need for collaborative professionalism. This collaboration should begin as soon as teachers report for the school year and include their perspectives of effective instruction with technology. School administrators and teachers must become learning partners in developing new pedagogical strategies that mirror our contemporary needs. As they cultivate these practices, their schools will be better prepared to weather the current storm of educational change and develop strategies and dispositions to navigate the complexities of post-COVID-19 schooling environments.

\section{REFERENCES}

Gonzales, M., \& Jackson, I. (2020, Aug. 5). Teaching and Leading with Technology in Title 1 Schools [Paper presentation]. International Council of Professors of Educational Leadership 2020 Virtual Conference.

Hargreaves, A., \& O'Connor, M. T. (2018). Solidarity with solidity: The case for collaborative professionalism. Phi Delta Kappan, 100(1), 20-24.

International Society for Technology Education (2020). ISTE standards. https://www.iste.org/standards

Mcleod, S., \& Richardson, J. W. (2011). The dearth of technology leadership coverage. Journal of School Leadership, 21(2), 216-240.

UNESCO (2020). COVID-19 Educational disruption and response. https://en.unesco.org/themes/education-emergencies/coronavirus-schoolclosures 
Weston, M. E., \& Bain, A. (2010). The end of techno-critique: The naked truth about 1: 1 laptop initiatives and educational change. Journal of Technology, Learning, and Assessment, 9(6),

Zheng, B., Warschauer, M., Lin, C. H., \& Chang, C. (2016). Learning in one-toone laptop environments: A meta-analysis and research synthesis. Review of Educational Research, 86(4), 1052-1084.

MIGUEL M. GONZALES, Ed.D., is an assistant professor in the educational policy and leadership program at the University of Nevada Las Vegas. His major research interests lie in the area of school technology leadership, leadership development and innovative school models and leadership. Email: miguel.gonzales@unlv.edu

IESHA JACKSON, Ed.D., is an assistant professor of teacher education at the University of Nevada Las Vegas. Her scholarship is situated in three main areas: student voice, culturally relevant and sustaining pedagogies, and equity-based, macro-level education policies. Email: Iesha.jackson@unlv.edu 